\title{
Redesain Ukuran Bak Pengolah Air Limbah Industri pada Wastewater Treatment Plant PT. Petro Jordan Abadi
}

\author{
Marsha Savira Agatha Putri ${ }^{1, *}$ \\ ${ }^{1}$ Program Studi Kesehatan Lingkungan, Fakultas Ilmu Kesehatan, Universitas Islam \\ Lamongan (marshasavira@unisla.ac.id) \\ * Correspondence author: marshasavira@unisla.ac.id; Tel.: (0322) 324706, 317116 \\ Received: 12 Desember 2019; Accepted: 28 Februari 2020; Published: 15 Maret 2020
}

\begin{abstract}
Abstrak
PT. Petro Jordan Abadi merupakan salah satu produsen asam fosfat di Kabupaten Gresik, Jawa Timur. Berdasarkan laporan tahunan tahun 2018, air limbah produksi semakin meningkat, dengan demikian hal ini menimbulkan oversludge yang disebabkan oleh ketidaksesuaian penginjeksian bahan kimia ke dalam bak pengolah maupun overflow debit aliran air limbah yang masuk pada salah satu unit pengolah dengan karakteristik air limbah yang belum memenuhi standar baku mutu yang ditetapkan oleh menurut Peraturan Gubernur Jawa Timur Nomor 72 Tahun 2013. Berdasarkan evaluasi yang dilakukan mengenai karakteristik dan dampak yang ditimbulkan, perlu dilakukan perancangan ulang dimensi unit pengolahan yang disesuaikan dengan kriteria desain, dan kebutuhan bahan kimia flokulan maupun koagulan. Untuk menganalisis dampak yang ditimbulkan oleh air limbah industri yang overflow, dilakukan metode pengujian sampel di Laboratorium PT. Petro Jordan Abadi. Evaluasi bak pengolah air limbah dilakukan dengan perhitungan spesifikasi masing-masing bak dan dibandingkan dengan kriteria desain menurut Metcalf and Eddy, 2003. Kemudian, dilakukan perencanaan spesifikasi masing-masing bak dan melakukan perhitungan ulang untuk memastikan bahwa perancangan yang baru telah memenuhi kriteria desain. Selain itu, juga menentukan alternatif bahan koagulan maupun flokulan yang diinjeksikan pada Primary Section dengan hasil uji jar test. Evaluasi kebutuhan koagulan dan flokulan dilakukan dengan cara membandingkan kebutuhan bahan tersebut untuk debit desain lama dengan desain baru. Hasil evaluasi mengenai karakteristik limbah yang mengalami overflow pada TK-6601 masih belum memenuhi baku mutu dan menimbulkan dampak terhadap lingkungan. Hal ini dikarenakan semua unit pengolah belum memenuhi kriteria desain. Sehingga, perlu dilakukan
\end{abstract}


pembesaran dan pengurangan ukuran dimensi. Dimensi bak yang diperbesar antara lain; Bak Ekualisasi I, serta Bak Flokulasi I dan II. Sedangkan dimensi bak yang diperkecil antara lain; pada seluruh Unit Koagulasi dan Sedimentasi, serta Bak Ekualisasi II dan III. Kebutuhan Lime Milk 5604,4 kg/hari, Alum 1204,7 kg/hari, Polimer 32,5 kg/hari, NaOH 0,9 m3/hari.

Kata kunci: Overflow, Oversludge, Redesain, Wastewater Treatment Plant

\section{Pendahuluan}

Kegiatan industri dan teknologi yang ada pada saat ini senantiasa menghasilkan limbah yang menimbulkan masalah bagi lingkungan seiring dengan bertambahnya tahun. Permasalahan ini dialami pula oleh PT. Petro Jordan Abadi. Perusahaan ini bergerak di bidang manufaktur kimia tepatnya yaitu pabrik Asam Fosfat. Seiring dengan meningkatnya produktivitas, maka limbah yang dihasilkan pun semakin meningkat pula.

Dengan demikian hal ini menimbulkan oversludge yang disebabkan oleh ketidaksesuaian penginjeksian bahan kimia ke dalam bak pengolah maupun overflow debit aliran air limbah yang masuk pada salah satu unit pengolah dengan karakteristik air limbah yang belum memenuhi standart baku mutu yang ditetapkan oleh [1]. Dengan demikian perlu dilakukan evaluasi teknis untuk perancangan ulang bak pengolah air limbah mengingat pula perusahaan tersebut akan membangun plant baru yaitu Purification Plant II. Adapun rumusan masalah pada penelitian ini adalah: bagaimana analisis bahaya air limbah terhadap aspek Keselamatan dan Kesehatan Kerja PT. Petro Jordan Abadi; Bagaimana evaluasi dimensi unit pengolahan air limbah di PT. Petro Jordan Abadi; Bagaimana evaluasi kebutuhan bahan kimia di unit pengolahan air limbah di PT. Petro Jordan Abadi; dan bagaimana perbaikan desain yang dapat diimplementasikan di Wastewater Treatment Plant PT. Petro Jordan Abadi.

\section{Metode penelitian}

Untuk menjawab rumusan masalah diatas, maka pertama kali yang dilakukan adalah pengumpulan data. Data-data yang dibutuhkan dalam penelitian ini adalah data primer dan sekunder. Data primer didapatkan dari hasil observasi maupun pengukuran oleh penulis. Data primer yang diambil oleh penulis dari PT. Petro Jordan Abadi adalah data monitoring $\mathrm{pH}$ per hari beserta keterangan lokasi titik sampling nya.

Sedangkan data sekunder didapatkan dari data historis yang merupakan arsip atau dokumen di perusahaan. Berikut ini adalah data-data sekunder yang didapatkan dari perusahaan: 
1. Data perencanaan awal

a. Data Kualitas Air Limbah

b. Data Spesifikasi Komponen Unit Pengolah Air Limbah

2. Data Layout Existing Wastewater Treatment
a. Process Flow Diagram (PFD)
b. Layout Plant

3. Data total jumlah debit/kuantitas dari:
a. Inlet (masukan) dari air limbah produksi
b. Outlet (keluaran) dari treated water yang di proses kembali
c. Outlet (keluaran) dari treated water yang di buang ke pipa outfall

\section{Data kebutuhan bahan kimia}

Setelah data terkumpul, langkah selanjutnya adalah menganalisis dampak pencemaran air limbah industri terhadap aspek K3 berdasarkan hasil pengujian dari setiap karakteristik air limbah yang dilakukan di Laboratorium PT. Petro Jordan Abadi. Setelah itu menentukan unit mana yang terjadi overflow menggunakan pendekatan hukum kesetimbangan massa pada persamaan (1) berikut menurut Spellman, 2004 [2]:

Inflow $=$ Outflow + Akumulasi

Setelah menentukan unit yang overflow, kemudian mengevaluasi masing-masing bak pengolah air limbah industri existing yang dibandingkan dengan kriteria desain. Bak pengolah yang terdapat pada PT. Petro Jordan Abadi antara lain: unit koagulasi, flokulasi, sedimentasi, dan ekualisasi. Berikut adalah beberapa persamaan untuk mengevaluasi masing-masing bak dibawah ini:

1. Mixing Tank (Bak Koagulasi dan Flokulasi)

a. Velocity gradient yaitu energi yang hilang dalam proses koagulasi dan flokulasi dalam persamaan (2) dibawah ini menurut Metcalf and Eddy, 2003 [3]:

$$
\text { Velocity gradient }=\sqrt{\frac{\text { Daya }}{\text { Velocity } \times \text { Volume }}}
$$

b. Waktu detensi yaitu waktu tinggal larutan campuran bahan kimia koagulan/flokulan pada bak yang dapat dilihat pada persamaan (3) menurut Metcalf and Eddy, 2003 [3] berikut:

$$
\text { Waktu detensi }=\frac{\text { Volume }}{\text { Debit }} \text {. }
$$


c. Mixing time yaitu waktu pengadukan yang dibutuhkan impeller dalam 1 kali pengadukan proses koagulasi dan flokulasi dalam persamaan (4) dibawah ini menurut Ulrich, 2003 [4]:

Mixing time $=12000 \times \sqrt{\frac{\text { velocity } x \text { Volume }}{\text { Daya }}} \times\left(\frac{\text { Volume }}{1 \mathrm{~m}^{3}}\right)^{\frac{1}{5}}$

d. Power Number yaitu daya pencampuran mixing tank yang dapat dilihat pada persamaan (5) menurut Metcalf and Eddy, 2003 [3]:

Daya $_{\text {input }}=$ Power number for Impeller $x$ densitas $x$ jumlah impeller $x$ Diameter impeller ${ }^{3}$

e. Ratio impeller yaitu perbandingan antara diamter tangki dengan tangki ekuivalen menurut [1] yang dapat dilihat persamaan dibawah ini:

$$
R=\frac{D}{T e}
$$

$\mathrm{R}=$ Ratio Impeller

$\mathrm{D}=$ Diameter Tangki $(\mathrm{m})$

$\mathrm{Te}=$ Tank Equivalent $(\mathrm{m})$ yang dapat ditentukan dari persamaan (7):

$\mathrm{Te}=1,13 \sqrt{\text { Luas alas }}$.

f. Tip Speed yaitu kecepatan pengadukan untuk slow mixing pada bak flokulasi:

Tip speed $=\frac{\text { diameter } \text { ba } \mathrm{k} \times \text { rotasi mixer }}{336}$

2. Sedimentation tank (Bak pengendap)

a. Over flow rate yaitu menyatakan besarnya air limbah per satuan luas tiap harinya, dengan satuan $\mathrm{m}^{3} / \mathrm{m}^{2}$ hari. Untuk menentukan OFR digunakan persamaan menurut [1 ] berikut:

Over flow rate $=\frac{\text { Debit }}{\text { Luas penampang }}$

b. Perhitungan waktu detensi menggunakan persamaan (3) dimana rumusnya sama dengan rumus waktu detensi pada bak koagulasi, flokulasi dan sedimentasi.

c. Weir loading rate (WLR) adalah beban pelimpah (dalam hal ini debit air) yang harus ditanggung per satuan waktu dan panjangnya. WLR dapat dihitung menggunakan persamaan (10) menurut [1]:

$W L R=\frac{\text { Debit }}{\pi \times \text { diameter tangki }}$

3. Equalization tank (Bak penampung) 
Evaluasi pada bak ini hanya menghitung waktu detensi yang dapat dilihat pada persamaan (2).

Setelah menyelesaikan perhitungan evaluasi pada masing-masing bak pengolah air limbah industri, kemudian merencanakan nilai-nilai yang menjadi faktor pemenuhan dari setiap parameter yang dibandingkan dengan kriteria desain menurut Metcalf\&Eddy, 2003. Serta melakukan perhitungan kembali untuk memastikan bahwa nilai-nilai tersebut telah memenuhi kriteria desain dari masing-masing unit. Hasil nilai perencanaan kemudian digambarkan bentuk perancangan nya. Kemudian, pengerjaan selanjutnya adalah merencanakan kebutuhan bahan kimia koagulan maupun flokulan untuk masing-masing unit yang sudah dirancang ulang, dengan cara membandingkan kebutuhan flokulan dan koagulan pada unit existing dan redesain. Gambar dibawah ini merupakan diagram alir pengerjaan penelitian berikut: 


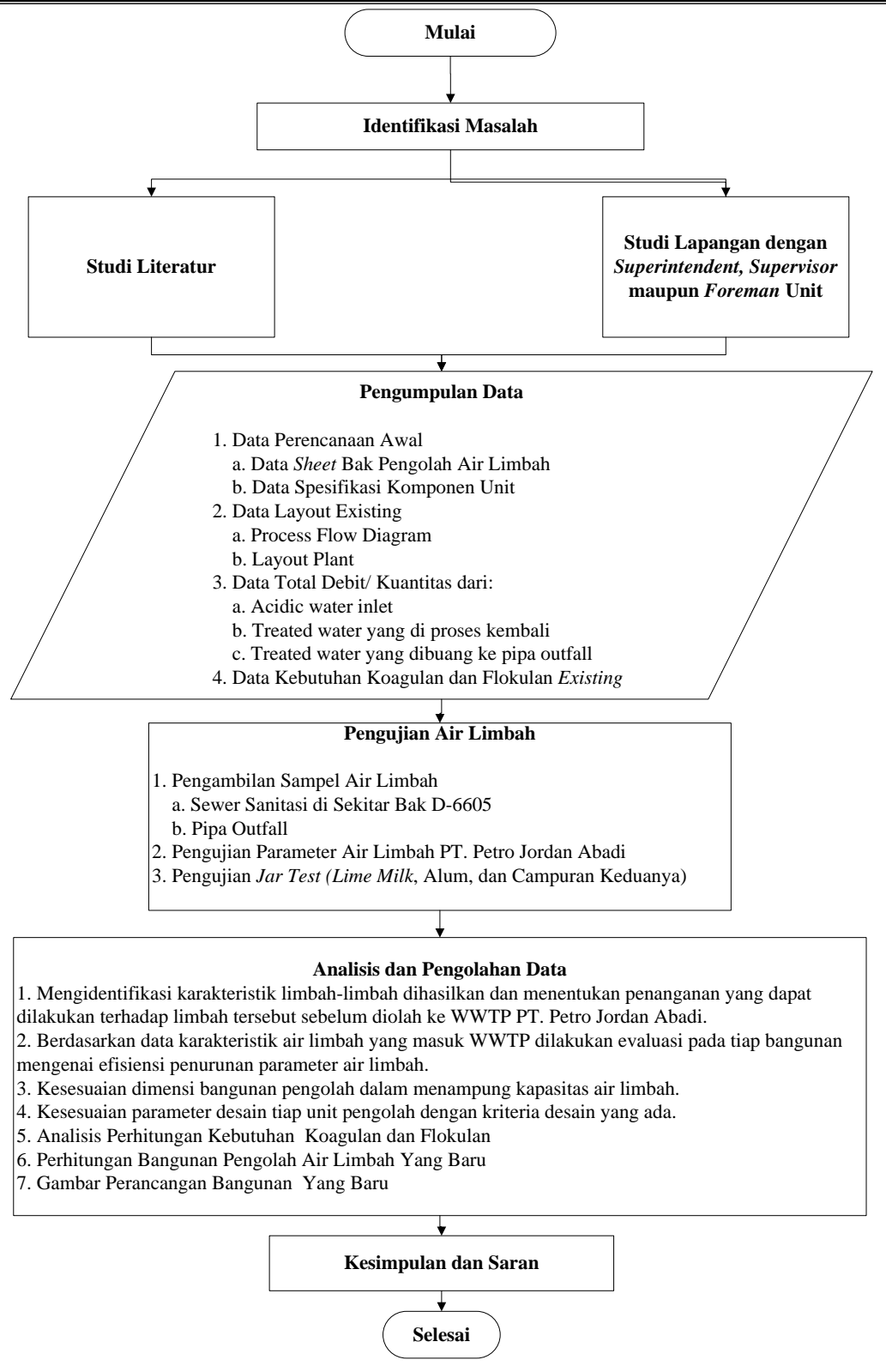

Gambar 1. Diagram Alur Penelitian

\section{Hasil dan pembahasan}

\subsection{Analisis karakteristik air limbah industri}

Menurut pemeriksaan laboratorium, karakteristik air limbah yang diolah pada WWTP dapat dilihat pada tabel 1: 
Tabel 1. Hasil Analisis Laboratorium mengenai Karakteristik Air Limbah yang Diolah di WWTP

\begin{tabular}{|c|c|c|c|}
\hline Parameter & $\begin{array}{c}\text { Acidic Water } \\
(\mathbf{m g} / \mathbf{L})\end{array}$ & $\begin{array}{c}\text { Neutralized Water } \\
(\mathbf{m g} / \mathbf{L})\end{array}$ & $\begin{array}{c}\text { Treated Water } \\
(\mathbf{m g} / \mathbf{L})\end{array}$ \\
\hline $\mathrm{pH}$ & 1,3 & 6,12 & 6,89 \\
\hline Phospat & 468,76 & 64,19 & 0,77 \\
\hline Fluor & 3525 & 112,2 & 2,04 \\
\hline TSS & 298 & 165 & 73 \\
\hline Sulphur & 438 & 200 & 95 \\
\hline
\end{tabular}

Sumber: (Analisis Laboratorium PT. Petro Jordan Abadi, 2019)

Selanjutnya kualitas outlet limbah yang overflow dibandingkan dengan Peraturan Gubernur Jawa Timur Nomor 72 Tahun 2013 Tentang Baku Mutu Air Limbah Bagi Industri Dan/Atau Kegiatan Usaha Lainnya di Jawa Timur, yang disajikan dalam tabel dibawah ini:

Tabel 2. Ketidaksesuaian Kadar Air Limbah yang Telah Diuji oleh Laboratorium PT. Petro Jordan Abadi berdasarkan Peraturan Gubernur Jawa Timur Nomor 72 Tahun 2013

\begin{tabular}{|l|c|c|c|c|}
\hline \multirow{3}{*}{$\begin{array}{c}\text { Jenis Limbah yang } \\
\text { Overflow }\end{array}$} & \multirow{2}{*}{ Parameter } & \multicolumn{2}{|c|}{$\begin{array}{c}\text { Besaran Nilai Parameter } \\
\text { (ppm) }\end{array}$} & \multirow{2}{*}{ Ket } \\
\cline { 2 - 5 } & & $\begin{array}{c}\text { Kondisi } \\
\text { Existing }\end{array}$ & Baku Mutu [2] & \\
\hline \multirow{3}{*}{ Acidic Water } & $\mathrm{pH}$ & 1,3 & $6-9$ & - \\
\cline { 2 - 5 } & $\mathrm{F}$ & 3525 & 15 & - \\
\cline { 2 - 5 } & $\mathrm{PO}_{4}$ & 468,76 & 20 & - \\
\cline { 2 - 5 } & $\mathrm{S}$ & 438 & $6-9$ & - \\
\hline \multirow{3}{*}{ Neutralized Water } & $\mathrm{pH}$ & 6,12 & 100 & - \\
\cline { 2 - 5 } & $\mathrm{F}$ & 112,2 & 20 & - \\
\cline { 2 - 5 } & $\mathrm{PO}_{4}$ & 64,19 & 100 & \\
\cline { 2 - 5 } & $\mathrm{S}$ & 200 & & \\
\hline Keterangan: $(\sqrt{ })=$ Sesuai $(-)=$ Tidak Sesuai & & & - \\
\hline
\end{tabular}

Sumber: (Analisis Laboratorium PT. PJA dan PerGub JatimNo. 72 Tahun 2013)

\subsection{Penentuan unit pengolah air limbah yang mengalami overflow}

Sebelum merancang ulang unit pengolahan air limbah pada WWTP PT. Petro Jordan Abadi, perlu dilakukan evaluasi banyaknya air limbah pada setiap unit pengolah yang overflow ke lingkungan menggunakan prinsip mass balance. 
Tabel 3. Hasil perhitungan kesetimbangan massa dan analisis penentuan unit pengolah air limbah yang mengalami overflow

\begin{tabular}{|c|c|c|c|c|c|c|}
\hline No & $\begin{array}{c}\text { Nama } \\
\text { Unit }\end{array}$ & Tipe Unit & $\begin{array}{c}\text { Debit } \\
\text { Inflow } \\
\left(\mathrm{m}^{3} / \mathbf{h}\right) \\
\end{array}$ & $\begin{array}{c}\text { Debit } \\
\text { Outflow } \\
\left(\mathrm{m}^{3} / \mathbf{h}\right)\end{array}$ & $\begin{array}{c}\text { Akumulasi } \\
\qquad\left(\mathbf{m}^{3} / \mathbf{h}\right)\end{array}$ & Ket \\
\hline 1 & TK-6601 & Bak Koagulasi I & 318,29 & 225,84 & 92,45 & $\mathrm{~V}$ \\
\hline 2 & TK-6602 & Bak Koagulasi II & 207,24 & 213,47 & $-6,22$ & - \\
\hline 3 & TK-6603 & Bak Flokulasi I & 215,37 & 220,31 & $-4,94$ & - \\
\hline 4 & D-6604 & Bak Sedimentasi I & 224,60 & 236,30 & $-11,70$ & - \\
\hline 5 & D-6605 & Bak Ekualisasi I & 106,33 & 114,17 & $-7,84$ & - \\
\hline 6 & D-6631 & $\begin{array}{l}\text { Bak Sedimentasi } \\
\text { II }\end{array}$ & 84,78 & 88,62 & $-3,84$ & - \\
\hline 7 & D-6632 & Bak Ekualisasi II & 50,37 & 53,86 & $-3,50$ & - \\
\hline 8 & TK-6651 & Bak Koagulasi III & 106,13 & 121,08 & $-14,95$ & - \\
\hline 9 & TK-6652 & Bak Flokulasi II & 119,73 & 122,41 & $-2,67$ & - \\
\hline 10 & D-6653 & $\begin{array}{l}\text { Bak Sedimentasi } \\
\text { III }\end{array}$ & 123,83 & 130,35 & $-6,51$ & - \\
\hline 11 & D-6654 & Bak Ekualisasi III & 60,59 & 63,32 & $-2,73$ & - \\
\hline
\end{tabular}

Nilai akumulasi positif menunjukkan bahwa debit inflow lebih besar daripada debit outflow, sehingga berpotensi overflow. Sebaliknya, jika debit inflow lebih kecil daripada debit outflow, sehingga tidak berpotensi overflow. Kemudian berdasarkan nilai akumulasinya dapat dikatakan bahwa aliran nya bersifat unsteady state atau fluktuatif, karena nilai akumulasi nya $\neq 0$ dan selalu berubah per hari nya.

\subsection{Evaluasi dan penentuan alternatif}

\subsubsection{Alternatif Pengolahan I mengenai evaluasi teknis kesesuaian unit existing sesuai dengan kriteria desain}

Berdasarkan hasil perhitungan yang mengacu pada persamaan (2) sampai dengan (10) mengenai evaluasi perhitungan kondisi existing unit pengolah air limbah di WWTP PT. Petro Jordan Abadi, tabel berikut menunjukkan perbandingan hasil perhitungan tersebut dengan kriteria desain pada masing-masing unit: 
Tabel 4. Perbandingan Parameter Kriteria Desain dengan Kondisi Existing pada Bak Koagulasi I (TK-6601)

\begin{tabular}{|c|c|c|c|c|}
\hline \multirow{2}{*}{ Parameter } & \multirow{2}{*}{ Satuan } & \multicolumn{2}{|c|}{ Besaran } & \multirow{2}{*}{ Ket } \\
\hline & & $\begin{array}{l}\text { Kriteria } \\
\text { Desain [1] }\end{array}$ & $\begin{array}{l}\text { Kondisi } \\
\text { Existing }\end{array}$ & \\
\hline Mixing Time & detik & $2-20$ & 91,99 & - \\
\hline $\begin{array}{l}\text { Detention } \\
\text { Time }\end{array}$ & menit & $0,5-2$ & 20 & - \\
\hline $\begin{array}{l}\text { Velocity } \\
\text { Gradient }(G)\end{array}$ & $\mathrm{s}^{-1}$ & $500-1500$ & 310,35 & - \\
\hline $\begin{array}{l}\text { Rotational } \\
\text { Speed }\end{array}$ & $\mathrm{r} / \mathrm{min}$ & $50-300$ & 240 & V \\
\hline $\begin{array}{l}\text { Ratio } \\
\text { Impeller }\end{array}$ & - & $0,4-0,6$ & 0,15 & - \\
\hline $\begin{array}{l}\text { Power } \\
\text { Number }\end{array}$ & - & $<0,6$ & 0,68 & - \\
\hline
\end{tabular}

Setelah mengevaluasi kesesuaian parameter kondisi existing dengan kriteria desain, maka langkah selanjutnya adalah melakukan perencanaan nilai-nilai yang mempengaruhi parameter dari masing-masing unit. Perencanaan nilai-nilai tersebut diharuskan memenuhi kriteria desain menurut [1].

Pada tabel dibawah ini merupakan nilai-nilai yang direncanakan:

Tabel 5. Perencanaan dan Rekomendasi dari Setiap Parameter pada Bak Koagulasi I

\begin{tabular}{|c|c|c|c|c|}
\hline Parameter & Satuan & Data Lapangan & Perencanaan & Rekomendasi \\
\hline Kapasitas Debit & $\mathrm{m} 3 / \mathrm{h}$ & 225 & 318,29 & $\begin{array}{c}\text { Kapasitas debit } \\
\text { disesuaikan dengan hasil } \\
\text { evaluasi rata- rata debit } \\
\text { pada Bulan Desember } \\
\text { Mixer Power }\end{array}$ \\
\hline kW & 110 & 150 & $\begin{array}{c}\text { Mixer Power diperkecil } \\
\text { agar Velocity Gradient } \\
\text { dan Power } \text { Number } \\
\text { sesuai dengan } \\
\text { kriteria desain }\end{array}$ \\
\hline Diameter & meter & 4,2 & 2,12 & $\begin{array}{c}\text { Diameter tangki } \\
\text { diperkecil karena dapat } \\
\text { mempengaruhi waktu } \\
\text { detensi, yang harus } \\
\text { memenuhi } \\
\text { kriteria desain }\end{array}$ \\
\hline Tinggi Tangki & meter & 5,5 & 3 & $\begin{array}{c}\text { Tinggi tangki diperkecil } \\
\text { karena dapat } \\
\text { mempengaruhi waktu } \\
\text { detensi, yang harus } \\
\text { memenuhi } \\
\text { kriteria desain }\end{array}$ \\
\hline Diameter Mixer & meter & 0,65 & 1 & Diameter Mixer \\
\hline
\end{tabular}




\begin{tabular}{|c|c|c|c|c|}
\hline \hline & & & $\begin{array}{c}\text { diperbesar menjadi } 1 \mathrm{~m} \\
\text { agar Power Number } \\
\text { dapat memenuhi } \\
\text { kriteria desain }\end{array}$ \\
\hline Rotasi Mixer & $\mathrm{rpm}$ & 240 & 300 & $\begin{array}{c}\text { Rotasi Mixer diperbesar } \\
\text { agar Power Number } \\
\text { dapat memenuhi } \\
\text { kriteria desain }\end{array}$ \\
\hline
\end{tabular}

Berdasarkan hasil analisis diatas, karena ukuran diameter dan tinggi pada Bak Koagulasi I diperkecil, maka tidak memerlukan lahan tambahan untuk perancangan ulang nya.

\subsubsection{Alternatif Pengolahan II mengenai Penentuan Bahan Kimia Alternatif pada Primary Section}

Permasalahan yang timbul pada perusahaan tersebut antara lain sering terjadi overflow pada Unit Koagulasi I (TK-66601) dan Unit Ekualisasi I (D-6605). Hal ini dikarenakan mixing time yang tidak sesuai dengan kriteria desain atau injeksi bahan kimia yang kurang tepat pada unit tersebut. Sehingga perlu dilakukan adanya Jar Test untuk menentukan bahan kimia yang terbaik dari Lime Milk, Alum, atau Campuran dari keduanya dengan rasio 1:3. Hasil pengujian Jar Test dipaparkan dalam Gambar 2 berikut:

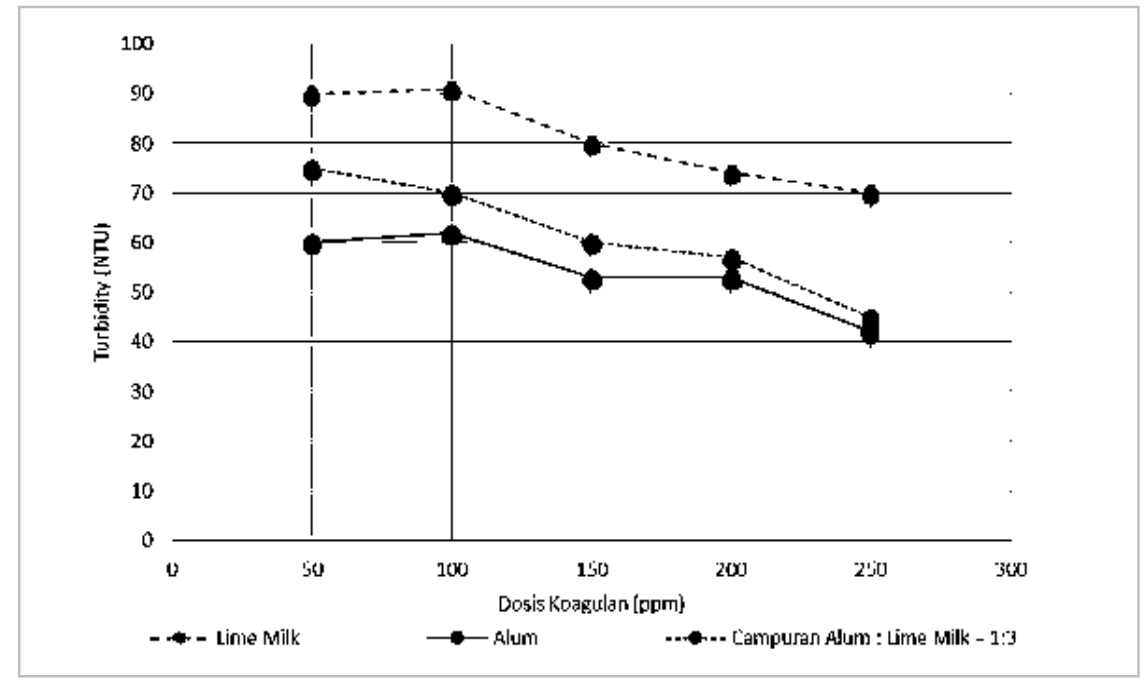

Gambar 2. Pengaruh Dosis Koagulan terhadap Kekeruhan

(Sumber: Analisis Lab. PT. PJA, 2016)

Berdasarkan Gambar 2, Alum dengan dosis yang semakin meningkat dapat menurunkan turbidity atau kekeruhan, begitu pula dengan Lime Milk dengan dosis yang sama. Nilai kekeruhan pada campuran Alum dengan Lime Milk pada perbandingan 1:3 semakin menurun apabila dosisnya semakin meningkat. Grafik nya berada diantara grafik tingkat kekeruhan limbah jika ditambahkan Lime Milk dan Alum. 
Untuk menentukan jenis pengolahan yang efektif dan efisien dari ketiga alternatif diatas, maka perlu untuk diketahui nilai efisiensi removal masing-masing parameter yang diujikan pada setiap alternatif tersebut yang dapat dilihat pada gambar (6) dibawah ini:

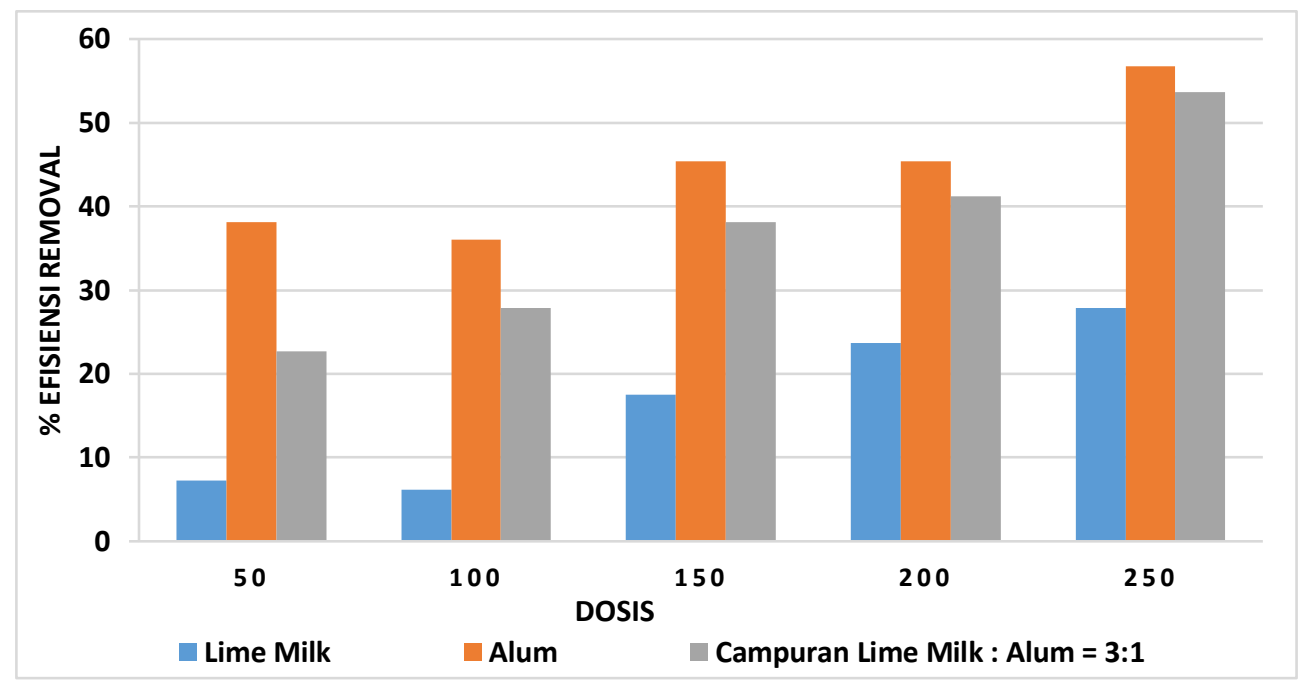

Gambar 3. Persentase Efisiensi Removal Terhadap Parameter Kekeruhan

Gambar 3 menunjukkan bahwa Alum menghasilkan efisiensi removal terhadap parameter kekeruhan paling tinggi dari ketiga alternatif koagulan. Pengaruh dosis koagulan terhadap suspended solid pada proses pengolahan limbah Acidic Water secara koagulasi dan flokulasi ditunjukkan pada Gambar 4:

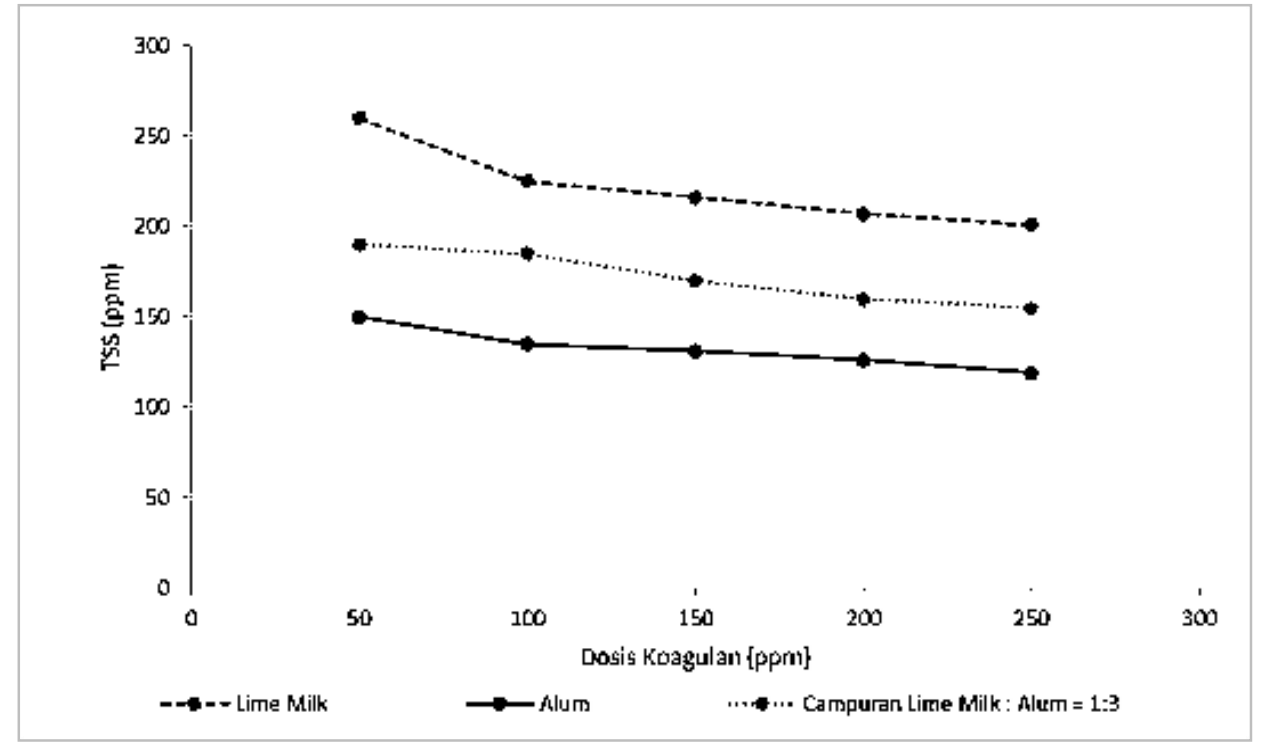

Gambar 4. Pengaruh Dosis Koagulan terhadap TSS

Berdasarkan Gambar 4, Alum dengan dosis yang semakin meningkat dapat menurunkan TSS, begitu pula dengan Lime Milk dengan dosis yang sama. Nilai kekeruhan pada 
campuran Alum dengan Lime Milk pada perbandingan 1:3 semakin menurun apabila dosisnya semakin meningkat. Grafik nya berada diantara grafik tingkat kekeruhan limbah jika ditambahkan Lime Milk dan Alum.

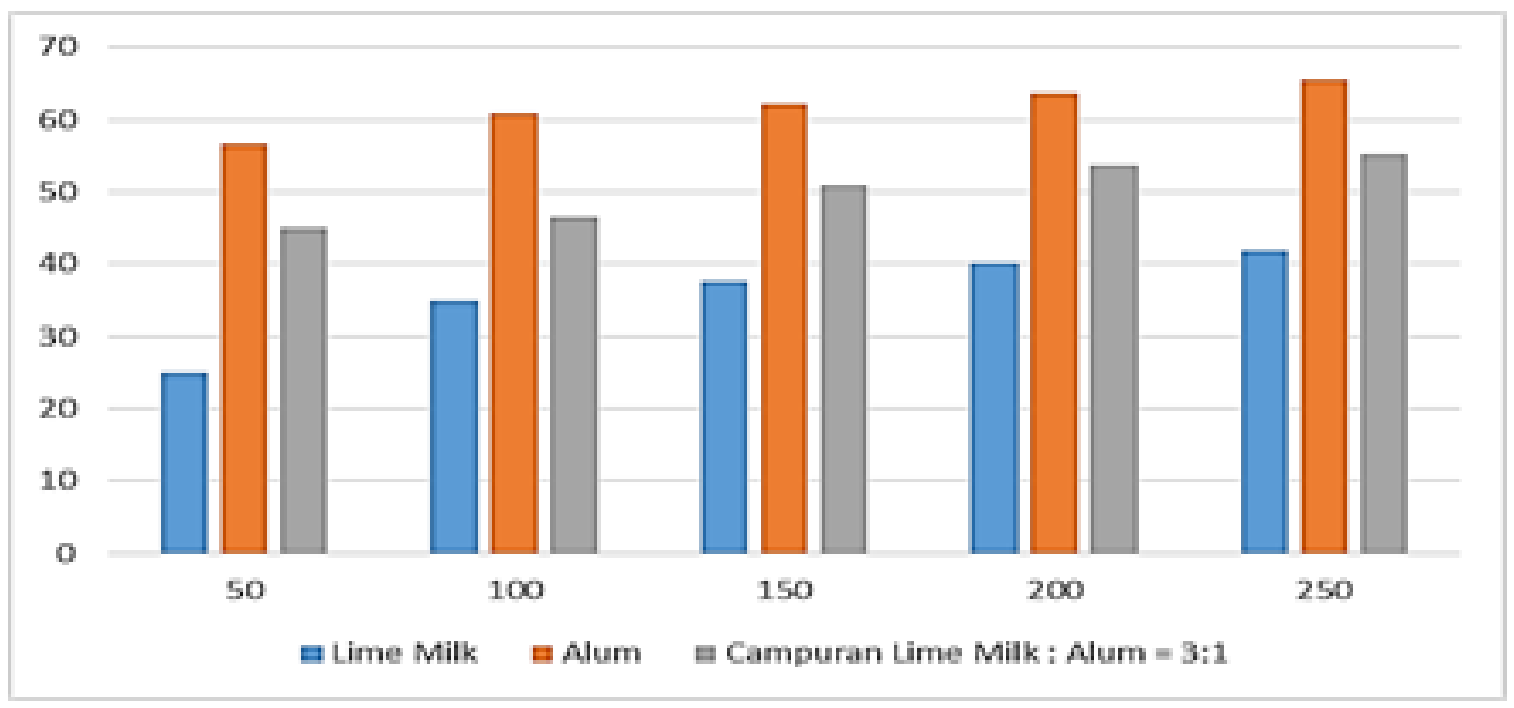

Gambar 5. Pengaruh Dosis Koagulan terhadap TSS

Gambar 5 menunjukkan adanya kenaikan persentase efisiensi removal pada setiap bahan koagulan. Namun nilai yang paling tinggi ditunjukkan oleh Alum. Dari penelitian ini juga telah dipelajari pengaruh dosis koagulan terhadap ukuran flok yang terbentuk, sebagaimana dapat dilihat pada Tabel 6 berikut:

Tabel 6. Pengaruh Dosis Koagulan terhadap Ukuran Flok yang Terbentuk

\begin{tabular}{|c|c|c|c|c|}
\hline \multirow{2}{*}{ No. } & \multirow{2}{*}{ Dosis (ppm) } & \multicolumn{3}{|c|}{ Ukuran Flok (cm)* } \\
\cline { 3 - 5 } & & Lime Milk & Alum & $\begin{array}{c}\text { Campuran Alum : } \\
\text { Lime Milk =1:3 }\end{array}$ \\
\hline 1 & 50 & 0,5 & 2,1 & 0,9 \\
\hline 2 & 100 & 0,6 & 2,1 & 1 \\
\hline 3 & 150 & 0,8 & 2,3 & 1,5 \\
\hline 4 & 200 & 0,8 & 2,3 & 1,55 \\
\hline 5 & 250 & 0,9 & 2,5 & 1,8 \\
\hline
\end{tabular}

Kombinasi penambahan Kuriflok dan Lime Milk yang hanya dapat membentuk flok dengan ukuran diameter yang lebih kecil atau sama dengan $0,9 \mathrm{~cm}$. Namun demikian dari hasil penelitian ini dapat diketakui bahwa baik pada penambahan Alum maupun Lime Milk telah dihasilkan flok yang sangat stabil. Sehingga dengan mempertimbangkan 
efisiensi removal, produksi sludge, harga, operasional, dan pemenuhan effluen terhadap baku mutu, maka alternatif yang dipilih adalah campuran alum : lime milk dengan rasio $1: 3$.

\subsection{Hasil Perhitungan Bangunan Pengolah Air Limbah yang Baru}

Untuk menentukan dan memastikan nilai hasil perhitungan dari setiap kriteria desain sudah sesuai dengan kriteria desain menurut [1], maka perlu dilakukan perhitungan ulang dari masing-masing unit. Hasil dari perhitungan ulang tersebut dapat dilihat pada tabel berikut:

Tabel 7. Hasil Perhitungan Bangunan Pengolah Air Limbah yang Baru pada Bak Koagulasi I

\begin{tabular}{|c|c|c|c|c|}
\hline \multirow{2}{*}{ Parameter } & \multirow{2}{*}{ Satuan } & \multicolumn{2}{|c|}{ Besaran } & \multirow{2}{*}{ Ket } \\
\cline { 3 - 5 } & & Kriteria Desain [1] & $\begin{array}{c}\text { Hasil } \\
\text { Perhitungan }\end{array}$ & \\
\hline Mixing Time & detik & $2-20$ & 19,78 & $\sqrt{ }$ \\
\hline Detention Time & menit & $0,5-2$ & 1,98 & $\sqrt{ }$ \\
\hline Velocity Gradient $(G)$ & $\mathrm{s}-1$ & $500-1500$ & 972,005 & $\sqrt{ }$ \\
\hline Rotational Speed & r/min & $50-300$ & 300 & $\sqrt{ }$ \\
\hline Ratio Impeller & - & $0,4-0,6$ & 0,4 & $\sqrt{ }$ \\
\hline Power Number & - & $<0,6$ & 0,48 & $\sqrt{ }$ \\
\hline \multicolumn{2}{|l}{ Keterangan: $(\sqrt{ })=$ Sesuai $(-)=$ Tidak Sesuai } \\
\hline
\end{tabular}

\subsection{Analisis perhitungan bahan koagulan dan flokulan}

Berdasarkan hasil perancangan ulang yang dilakukan pada sub bab sebelumnya, dapat disimpulkan bahwa dimensi bak-bak pengolah air limbah industri pada unit koagulasi dan flokulasi. Sehingga diperlukan analisis jumlah kebutuhan bahan kimia koagulan dan flokulan dengan cara perhitungan perbandingan matematis kebutuhan bahan koagulan dan flokulan pada unit eksisting dengan unit yang sudah dirancang ulang pada Tabel 8 berikut:

Tabel 8. Hasil Perhitungan Bangunan Pengolah Air Limbah yang Baru pada Bak Koagulasi I

\begin{tabular}{|l|l|l|c|c|c|}
\hline \multirow{2}{*}{ Nama Bahan } & \multicolumn{2}{|l|}{$\begin{array}{l}\text { Kapasitas Debit } \\
(\mathbf{Q})(\mathrm{m} 3 / \mathbf{j a m})\end{array}$} & \multicolumn{3}{|c|}{ Kebutuhan per Hari } \\
\cline { 2 - 6 } & Qo & $Q_{1}$ & Ko & K1 & Satuan \\
\hline
\end{tabular}




\begin{tabular}{|c|c|c|c|c|c|}
\hline \hline Lime Milk & 225 & 525,53 & 4799 & 5604,4 & $\mathrm{~kg}$ \\
\hline Polimer & 225 & 215,37 & 34 & 32,5 & $\mathrm{~kg}$ \\
\hline Alum & 125 & 106,13 & 1419 & 1204,7 & $\mathrm{Kg}$ \\
\hline $\mathrm{NaOH}$ & 125 & 119,73 & 1 & 0,9 & $\mathrm{~m} 3$ \\
\hline
\end{tabular}

Berdasarkan tabel diatas, maka dapat disimpulkan bahwa apabila kapasitas debit mengalami kenaikan dari desain awal dengan redesain, maka kebutuhan koagulan per hari, semakin meningkat pula.

\section{Kesimpulan}

Hasil evaluasi mengenai karakteristik limbah yang mengalami overflow pada TK-6601 masih belum memenuhi baku mutu dan menimbulkan dampak terhadap lingkungan. Hal ini dikarenakan semua unit pengolah belum memenuhi kriteria desain. Sehingga, perlu dilakukan pembesaran dan pengurangan ukuran dimensi. Dimensi bak yang diperbesar antara lain; Bak Ekualisasi I, serta Bak Flokulasi I dan II. Sedangkan dimensi bak yang diperkecil antara lain; pada seluruh Unit Koagulasi dan Sedimentasi, serta Bak Ekualisasi II dan III. Kebutuhan Lime Milk 5604,4 kg/hari, Alum 1204,7 kg/hari, Polimer 32,5 kg/hari, NaOH 0,9 m3/hari.

Acknowledgments: Terima kasih, penulis sampaikan kepada segenap crew PT. Petro Jordan Abadi yang membantu penulis dalam pengumpulan data sehingga penulis dapat menyusun penelitian ini dengan baik.

Conflicts of Interest: The authors declare no conflict of interest.

\section{Daftar Pustaka}

[1] Peraturan Gubernur Jawa Timur Nomor 72 Tahun 2013 mengenai Baku Mutu Air Limbah Bagi Kegiatan Industri

[2] F. E. Spellman, Mathematics Manual for Water and Wastewater Treatment Plant Operators, New York: CRC Press, 2004.

[3] Metcalf and Eddy, Wastewater Engineering : Treatment and Reuse (Fourth Edition), New York: McGraw Hill Companies, Inc, 2003.

[4] G. D. Ulrich and P. T. Vasudevan, A Guide to Chemical Engineering Process Design and Economics Second Edition, New Jersey: Marcel

Dekker, Inc, 2003. 